\title{
$O$ ENS REALISSIMUM E A EXISTÊNCIA: NOTAS SOBRE O CONCEITO DE IMPESSOALIDADE EM SER E TEMPO, DE MARTIN HEIDEGGER
}

\author{
Róbson Ramos dos Reis*
}

RESUMO Neste artigo examinamos a noção de impessoalidade (das Man), apresentada em Ser e Tempo, de Martin Heidegger. Tomando como via interpretativa a análise de uma comparação estabelecida por Heidegger entre o das Man e o conceito de ens realissimum, sustenta-se que a impessoalidade possui uma função ontológica central no programa da ontologia fundamental. $O$ modo de ser impessoal representa a fonte elementar de toda inteligibilidade, de modo análogo ao modo como o conceito de ens realissimum, na tradição ontoteológica, significou o fundamento de determinação de coisas em geral. Assim, o paralelo entre as noções de impessoalidade e ens realissimum permite captar a natureza social da projeção de ser pela compreensão de ser que caracteriza o ser humano.

ABSTRACT In this paper we examine the notion of impersonality (das Man) presented in Heidegger's Being and Time. Taking as interpretative guideline the analysis of a comparison made by Heidegger between the das Man and the concept of ens realissimum, we maintain that the impersonality has a central ontological function within the program of the fundamental ontology. Like the concept of ens realissimum in the ontoteological tradition, which played the rolle of ground of determination for things in generall, the impersonal manner of being represents the elemental source of all inteligibility.

* Departamento de Filosofia/UFSM

KRITERION, Belo Horizonte, no 104, Dez/2001, p.113-129 
The parallel between the notions of impersonality and ens realissimum enables then a grasping of the social nature of the projection of being by the human understanding of being.

Palavras-chave Heidegger - impessoalidade - ens realissimum

\section{Ontoteologia, analítica existencial e ontologia fundamental}

Ontoteologia é a expressão usada por Heidegger para designar um traço essencial da metafísica ocidental. Apresentar as determinações do conceito de ser a partir dos traços fundamentais de um ente particular, seria a orientação geral da confusão entre ser e ente. O componente ontoteológico estaria presente na convergência das duas direções de investigação da filosofia primeira. Ou seja, a busca das determinações dos entes enquanto entes e daquelas determinações próprias ao ente supremo encontraria unidade na pergunta pelo ente como tal e em seu todo, isto é, no fundamento unificador e determinador dos entes em geral. De um ponto de vista histórico, a expressão ontoteologia não é uma criação técnica da filosofia de Heidegger. Segundo o conhecido estudo de Dieter Hendrich (1960, p. 1 n.), "ontoteologia" teria sua origem na obra de Kant, numa acepção mais específica, e restrita ao contexto da assim chamada prova ontológica da existência de Deus. De acordo com Hendrich, a história do desenvolvimento da ontoteologia na filosofia moderna, em particular com os neoplatônicos de Cambridge, teria mostrado a dependência do conceito de ens necessarium (presente na assim chamada segunda forma do argumento ontológico) em relação à primeira forma do argumento, que repousa no conceito de ens realissimum. A possibilidade do argumento ontológico seria a disputa decisiva não apenas para a teologia racional, mas para o inteiro projeto de uma teoria metafísica do mundo, cujo fundamento estaria no conceito de um ente absolutamente necessário (Hendrich, 1960, p. 5).

Heidegger tomou em consideração de modo expresso a discussão kantiana da prova ontológica. Na doutrina de Kant sobre o ser, seja em sua tese negativa (ser não é um predicado real), seja em sua tese positiva (ser é posição absoluta ou posição relativa), Heidegger via uma ligação necessária com a investigação ontológico fundamental (GA 24, s. 58). ${ }^{1}$ Sabe-se que não há lugar para algo assim como uma metafísica transcendente no programa com-

1 Para fins de referência das obras de Heidegger, utilizarei a sigla GA (Gesamtausgabe) e o número do volume considerado, em conformidade com a lista bibliográfica ao final, à exceção de Ser e Tempo, com a sigla SZ. 
pleto da investigação ontologia fenomenológico-hermenêutica. ${ }^{2} \mathrm{O}$ problema do sentido do ser, bem como os restantes problemas fundamentais da ontologia, não se referem a nenhuma dimensão dissociada do domínio dos objetos acessíveis aos existentes humanos. A própria Teologia, tomada como uma ciência positiva, é concebida por Heidegger como sendo uma ciência histórica (GA 9, s. 56). De outro lado, mesmo a relação entre ontologias regionais, ontologia formal, e ontologia fundamental não é pensada em termos de alguma derivação a partir de conceitos últimos. Também é evidente que as exigências da ontologia fundamental, (e de todo o pensamento sobre o ser na obra de Heidegger) destacam enfaticamente as insuficiências de princípio na formulação do problema ontológico ao longo da história da filosofia ocidental. Um caso subsidiário está presente na afirmação de que o modo de ser próprio dos seres-humanos exigiria o redimensionamento global do próprio marco categorial da ontologia. ${ }^{3}$ A retomada fenomenológica da temática da ontologia comprometia-se, portanto, com uma avaliação crítica de todo o repertório conceitual da tradição metafísica. Assim sendo, inclusive o próprio vocabulário da ontoteologia (ens necessarium e ens realissimum) deveria ser visto como estranho à analítica da compreensão de ser, bem como aos problemas ontológicos que dela são dependentes.

Entretanto, a noção de ens realissimum aparece positivamente no corpo da analítica da existência, e com uma função explicativa central. Ao concluir a exposição da constituição social da existência humana, e tendo caracterizado o modo de ser impessoal (das Man) como a forma na qual se sustenta a identidade existencial cotidiana, Heidegger afirma que, existindo no modo impessoal, o Dasein seria um ens realissimum (SZ, p. 128). No presente trabalho examinaremos o significado da comparação entre a existência impessoal (das Man) e o ens realissimum. Como será visto a seguir, a indicação sugerida com o uso deste conceito é relevante em duas direções. Sustentamos que, bem entendida, tal passagem de Ser e Tempo é uma chave interpretativa central para a reconstrução da historicidade existencial elementar, e para a caracterização estruturalmente social do desvelamento de ser. Para justificar tal afirmação, lançamos mão de uma via indireta, examinando um aspecto da noção de ens realissimum apresentado na crítica de Kant ao argumento onto-

2 Um esboço de um tal programa da ciência do ser foi apresentado nos Problemas Fundamentais da Fenomenologia.

3 Inicialmente, os entes humanos seriam pertencentes a um domínio ontológico especial, não apenas porque não seriam portadores de propriedades nos moldes como outros entes o seriam, mas antes disso, seriam determináveis apenas segundo modos e possibilidades existenciais. Que o modo de ser humano é apenas o da possibilidade existencial repousa, em última instância, no factum da compreensão de ser, que desvela ser e torna possível o aparecer do entes. 
lógico. Procederemos em quatro etapas. Primeiro, resumiremos o problema da primazia do modo de ser inautêntico, que resulta da ontologia da existência como determinada pela possibilidade. A seguir, apresentaremos uma reconstrução do status normativo do modo de ser inautêntico e do existencial da impessoalidade (das Man). Terceiro, faremos uma análise da comparação do modo de ser impessoal com o conceito de ens realissimum, em particular no tocante às qualificações exigidas pelo o tipo ontológico que é o Dasein. Por fim, concluiremos com as implicações do tópico examinado para a questão da socialidade da existência humana enquanto Dasein.

De modo geral, tomamos como base interpretativa da analítica existencial uma posição que afirma o caráter constitutivo da socialidade existencial, que é determinante da própria instauração do sentido pela compreensão de ser. Uma tal posição requer, naturalmente, uma reconstrução positiva e não valorativa do modo de ser impessoal (das Man). Com base numa concepção relacional da dinâmica entre autenticidade e inautenticidade sustentaremos tese de que a primazia da inautenticidade significa a instauração de padrões de comportamentos existenciais, regulados social e intersubjetivamente. A singularização no modo de ser autêntico tem o sentido de uma alteração na relação com a regra dispositiva do padrão, por meio de uma relação explicitada com tal regra padronizante, que inclui expressamente a formação de novas regularidades capazes de padronização e de um nova explicitação. Assim sendo, o modo de ser autêntico não significa um isolamento de uma socialidade constitutiva, mas, ao contrário, é uma nova atitude em face de tal socialidade, capaz de reconhecer a autoridade da regra impessoalmente padronizada, ou propor novas formações regulares, capazes de explicitação autorizativa. A comparação entre a impessoalidade da existência e o ens realissimum não é, portanto, uma referência casual em Ser e Tempo, mas nos coloca no núcleo mesmo da ontologia fundamental.

\section{A categoria da existência: possibilidade e socialidade.}

Na raiz da ontologia fenomenológico-hermenêutica está a discussão crítica da pretensão de universalidade da tese ontológica da tradição ocidental, segundo a qual todo e qualquer ente, na medida em que é ente, pode ser articulado em termos de essência e existência. Ou seja, Heidegger levanta a suspeita de que possa haver uma classe de entes que não pode ser interpelada como portadora de determinações reais e de uma existência possível. De modo geral, uma das grandes teses da fenomenologia de Heidegger consiste em afirmar que o repertório conceitual da metafísica ocidental reconheceria apenas um único nível de diferenciação ontológica, a saber, aquele que discrimi- 
na critérios de identificação e individuação baseados na posse de propriedades ou atributos. Um novo domínio de problemas deveria ser acrescido à ontologia, relativo ao modo em que objetos podem ser portadores de propriedades: não apenas devemos nos perguntar se e o que é um objeto, mas também e sobretudo como ele é, indicando uma tal qualificação que a maneira como um ente é portador de determinações não pode ser pensada de modo simples (GA 24, ss. 169-71.

Uma tal exigência também tem a pretensão de que há um domínio de entes diferenciado de todos os demais em função do modo como as suas instâncias individuais podem ser portadoras de atributos. Ou seja, há entes cuja peculiaridade consiste em não ter propriedades do mesmo modo como outros tipos identificáveis de entes. Entes cujas "propriedades" não são atributos, mas apenas modos ou possibilidades. Para designar um tal modo de ser, Heidegger emprega a expressão existência. Dito de outro modo, todos os exemplares individualizáveis de entes existentes (nesta acepção do termo existência) não são instâncias de um tipo, não são casos pertencentes a um domínio discriminado por um conceito. É claro que em sentido amplo podemos nos referir a um domínio específico de entes, mas aqui estaríamos lidando com um predicado referente ao modo de possuir determinações: entes que possuem ou não propriedades, e entes que possuem apenas modos. Na medida em que tal ente não é portador de propriedades, mas apenas modos de ser, sua identidade própria é uma tarefa, algo a ser completado, inteirado e consumado. Para tais entes impõe-se uma relação consumatória com sua própria identidade ontológica não previamente assegurada. A identidade possível para entes existentes a tarefa de inteirar, uma constante efetivação. Uma primeira e fundamental conseqüência da ontologia da existência está em a tarefa de estabelecer a própria identidade somente pode ser levada a cabo por aquele singular que a empreende e por ninguém mais. Há uma singularidade irredutível em tal categoria ontológica, que implica a ocasionalidade e a indexicalidade intrínseca dos modos de referir-se linguisticamente a tais entes. ${ }^{4}$

A tese ontológico-existencial tem suas raízes em uma concepção das modalidades, que exige a ampliação para além de modalidades aléticas, afirmando a necessidade de diferenciar as modalidades próprias aos entes caracterizados como Dasein e as modalidades pertinentes a todos os que podem ser subsistentes (utensílios, objetos, objetos matemáticos incluídos). ${ }^{5}$ Assim,

4 Como é bem conhecido, o traço ontológico da categoria da existência, a Jemeinigkeit, que impõe a indexicalidade no modo de referir-se a tais indivíduos, representará a base para uma doutrina dos conceitos e enunciados filosóficos como indicações fomais. Para qualificar tecnicamente um tal "domínio" ou "categoria" ontológica Heidegger escolhe o termo Dasein

5 Uma excelente exposição da noção de possibilidade existencial está em Blattner (pp. 34-6) . 
devemos discriminar a possibilidade lógica, a possibilidade objetual (incluída não apenas a possibilidade física, mas referente a qualquer ente distinto do existente), e a possibilidade existencial. No domínio da existência a possibilidade tem predominância sobre efetividade e necessidade, o que traz dificuldades para um conceito existencial de determinidade.

Não podemos examinar agora a noção de possibilidade existencial. Destacamos apenas o seu aspecto central, segundo o qual as possibilidades existenciais são habilidades, são competências que cada um pode desempenhar. A existencialidade implica que estar em uma dada característica quer dizer ser capaz de um desempenho específico. As características dos entes existentes são, portanto, características de habilidade, diferentemente de características de estado, as quais podem ser propriamente chamadas de qualidades ou atributos. O marco conceitual aqui esboçado é mais complexo, pois se deve introduzir distinções internas na noção de possibilidade, da qual resulta uma visão dual da descrição dos entes que são Dasein. Os existentes podem ser descritos como portadores de propriedades, mas com a abstração de sua especificidade ontológica. A determinidade ôntica não estará definida, portanto, pela posse efetiva de características de estado, mas em termos existenciais. A facticidade do existente é obtida pela introdução do componente afetivo, em que as possibilidades lançadas estão disposicionalmente especificadas (Blattner, 1999). As disposições afetivas determinam a visualização de possibilidades (Han, 1999, s. 19), fazendo a discriminação entre possibilidades que importam e aquelas que não afetam, dirigindo os projetos para possibilidades determinadas de ação, em detrimento de outras, indiferentes. A descrição aqui introduzida não está completa, pois ainda deveria ser considerado o caráter propriamente descobridor que Heidegger atribui ao lançar-se em possibilidades, no qual se pode reconhecer tanto a discussão crítica com a noção de intencionalidade da consciência, como a dimensão propriamente pragmática da autoridade criterial ontológica. Neste último caso, estaria em jogo uma concepção da identificação e individuação ontológica a partir dos desempenhos efetivos dos existentes em face de algo. A constituição ontológica pode ser vista como a instituição a partir desempenhos que são instâncias de padrões responsivos e recognitivos (Haugeland, 1982 e Brandom, 1992). As condições de sistematicidade estrita que regulam uma tal ontologia de relações internas impõem o descobrimento concomitante de entes diferentes do Dasein (utensílios ou objetos), assim como de outros que lhe são idênticos.

Uma ontologia que atribui à "categoria" da existência um estatuto diferenciado em relação a outros domínios possíveis de objetos permite uma elaboração original da socialidade humana. Pode-se dizer que é uma tese central de toda a analítica existencial a afirmação do caráter primitivo da noção de 
outras pessoas (Mulhall, pp. 64-5). Ou seja, o traço da socialidade da existência é concebido como irredutível e originário. ${ }^{6}$ Neste caso, a estrutura do sercom não apenas estará presente nas possibilidades em que cada existente está projetado, mas ela desempenha um papel constitutivo no próprio desvelamento de ser. Sendo possibilidade lançada, cada existente é singularmente qualificado por maneiras de ser, entendidas como habilidades e competências nas quais se está lançado. Com a projeção em tais possibilidades especificam-se objetivos e metas para desempenho, na sustentação dos quais são articuladas as condições de relevância, a significatividade. Ora, tais habilidades são delineadas como papéis normativamente estruturados por regras. ${ }^{7}$ Em sentido estrito tal regulamentação não quer dizer apenas uma simples padronização típica. $\mathrm{O}$ aspecto normativo presente implica uma dimensão coercitiva na padronização, ou seja, as habilidades sustentadas são reguladas de um modo prescritivo delimitado. O ponto decisivo é que em princípio as habilidades podem ser exercitadas por qualquer um. Ou seja, os papéis recebem uma estabilização impessoal e interpessoal. Assim sendo, dominar normas significa guiar-se por regras de caráter público, significa pertencer a um contexto no quais outros também seguem ou são capazes de acatar a norma. Trata-se de regras públicas partilhadas praticamente em um mundo comum, de modo que o existente que nelas está lançado é uma unidade de responsabilização em termos ativos e passivos (Haugeland, 1982, p. 21). Uma análise mais detalhada mostrará que papéis também são definidos contrastivamente, isto é, delimitam-se em campos de contrastes (Guignon, 1983, pp. 105-6). Consequentemente, as possibilidades existenciais estão referidas a redes de papéis entrelaçados.

Assim entendida, a socialidade da existência determina a estrutura da impessoalidade como sendo o conjunto de tais normas, formando uma padrão geral, abarcante e estruturado. Das Man é a denominação para um constructo impessoal, englobando normas definidoras de papéis e tipos de ações responsivas. Tais normas demandam indivíduos para realizá-las e instituí-las,

6 É amplamente conhecido na literatura que este capítulo de Ser e Tempo apresenta ambigüidades, tensões, e até mesmo inconsistências em seus conceitos centrais. De outro lado, também é manifesto que a temática é relativamente pouco desenvolvida no corpo geral da obra, com muitas indicações ainda por elaborar. Neste respeito, qualquer pretensão hermenêutica deve observar antes de mais nada a distinção entre o significado propriamente dito da doutrina e a ordem de sua tematização e exposição. Que a tematização da socialidade do Dasein inicie com o reconhecimento da presença do outro a partir do encontro no mundo das ocupações funcionais obedece a uma exigência metodológica. Daqui não se segue que o outro seja reconhecido apenas como parceiro mais ou menos indiferente no mundo das ocupações.

7 Apesar de que a noção de papel deva ser restringida em seu emprego na ontologia existencial, ela pode ser adotada como uma indicação interpretativa a ser avaliada retrospectivamente. Acerca do debate em torno da interpretação da cotidianidade inspirada em Wittgenstein, ver: Haugeland, Guignon, Dreyfus, Mulhall e Olavson. 
mas podem subsistir independentemente destes mesmos indivíduos (Dreyfus, 1992, p. 165). Todos os traços que Heidegger destaca para os comportamentos normalizados, na análise do das Man, são derivados da natureza normativa e estruturada do impessoal. Distancialidade, sujeição, medianização, nivelamento, desencargo, e satisfação de demandas são determinantes neutros de padrões comportamentais submetidos à papeis e normas sociais. E Heidegger afirma o caráter estrutural do fenômeno:

\footnotetext{
“O impessoal é um existencial, e como fenômeno originário pertence à constituição positiva do Dasein, também ele possui distintas possibilidades de sua concretização segundo o modo do Dasein. A força e a expressividade de seu domínio podem variar historicamente." (SZ, s. 129).
}

Daqui ainda se conclui que, independentemente de sua modificação histórica, a variação atinge a força impositiva e sua expressão explicitativa, mas não o factum de que a existência social é impessoalmente qualificada, no sentido de um componente ontológico formal invariável. Estas considerações são suficientes para iniciar o exame da função de desvelamento que a socialidade deve satisfazer, a fim de manifestar o seu efetivo status ontológico. Acreditamos que isto é indicado pela comparação entre impessoalidade e ens realissimum, que tematizamos a seguir.

\section{Ens realissimum e impessoalidade.}

Considerando que o domínio da existência compreende instâncias individuais que não podem ser adequadamente descritas como portadoras de propriedades, então a noção de impessoalidade refere-se à consistência possível neste campo ôntico. Consequentemente, a impessoalidade possui uma relevante significação ontológica, seja para a ontologia fundamental, seja para a ontologia da existência. Ao alcançar este ponto da interpretação, Heidegger faz duas afirmações centrais:

\footnotetext{
"Esta maneira de ser não quer dizer uma diminuição da facticidade do Dasein, tão pouco como o impessoal enquanto o ninguém é um nada. Ao contrário, neste modo de ser o Dasein é um ens realissimum, caso 'realidade' seja compreendida de acordo com o ser que é conforme ao Dasein.” (SZ, s. 128)
}

A última frase da passagem exemplifica a operação metodológica de destruição que está evidentemente em jogo aqui, cuja análise exigiria tanto uma exposição da história do conceito de ens realissimum, quanto da apropriação construtiva promovida por Heidegger. Dado que esta afirmação sobre o Dasein e o ens realissimum é deixada sem comentário, sugerimos uma via 
indireta para dar início à sua análise. O cerne da apropriação fenomenológica pode ser apresentado a partir uma comparação com o tratamento dado por Kant ao problema da origem racional da noção de ens realissimum, em especial através das características fundacionais desta noção.

É na discussão crítica da teologia racional, no exame das provas da existência de Deus apresentado na Crítica da Razão Pura, em particular na prova ontológica, que Kant considera o conceito de ens realissimum. Não é relevante aqui a pretensão e a estratégia crítica de Kant. O contexto para onde dirigir o foco da análise é o da dedução metafísica do Ideal da razão pura, isto é, a exposição de como a razão gera a idéia teológica. Também não é de interesse agora a suficiência da argumentação de Kant, nem mesmo o exame da plausibilidade do próprio empreendimento. Interessa, antes de mais nada, destacar as características ontológicas da noção de ens realissimum, que são mostradas precisamente em relação à sua gênese a partir de princípios da ontologia geral.

Kant toma por base as doutrinas ontológicas da escola de Leibniz-Wolf, em particular nas formulações de Baumgarten. ${ }^{8} \mathrm{O}$ mecanismo expositivo consiste em mostrar como um princípio de determinação de coisas em geral (um princípio ontológico, portanto) tem uma pressuposição necessária, sob a qual opera um procedimento hipostasiante que dá origem ao Ideal da razão na forma do conceito de ens realissimum. Trata-se do princípio da determinação completa das coisas (principium omnimodae determinatio), que diz: em relação a todos os predicados possíveis das coisas, cada uma em particular está determinada em relação a um dos pares de predicados contraditórios. Para que isto seja o caso, a determinação efetiva de cada coisa individual é relacional, ou seja, é obtida por referência comparativa ao conjunto de todos os predicados possíveis das coisas. A determinação completa pressupõe a noção de um conjunto de todos os predicados, o conjunto da inteira possibilidade: omnitudo realitatis. Ao pensarmos tal noção como denotando um ente individual, que seria o portador de todas as propriedades (tomadas como realidades positivas, compossíveis e primitivas), estamos diante do Ideal da razão pura, o ens realissimum. Kant introduz a diferença entre negação e afirmação transcendentais, para estabelecer a prioridade das realidades sobre suas negações, o que será relevante para conceber o ens realissimum como fundamento de todas as coisas singulares determinadas. ${ }^{9}$

8 Tomamos em consideração a conhecida análise de K Smith (1962, pp. 522-27), bem como os desenvolvimentos em Sala (1990) Ameriks (1992), Wood (1992), Dell'Oro (1994).

9 É evidente que Kant discutirá a legitimidade deste passo, bem como a possibilidade de termos um conceito completo de coisas indivichais. Não porque as coisas individuais não estejam inteiramente deteminadas - 
Daqui destacamos o aspecto fundacional do conceito de ens realissimum, que diz respeito à pressuposição exigida para o conceito de coisas singulares. Coisas singulares são pensáveis como inteiramente determinadas, e para isso deve-se supor o termo relacional de comparação. A determinidade completa de um objeto é dada pela participação e negação relativamente ao inteiro conjunto das propriedades, que não se caracteriza, entretanto, como uma relação de inclusão, ao modo de uma relação todo-parte. Além disso, o ens realissimum funciona como um pressuposto para a individuação de coisas singulares. A inteira determinação atual de um ente singular é o seu princípio de individuação, que tem por base a idéia do conjunto de toda a realidade. Isso tudo é o que faz do ens realissimum o fundamento de todas as coisas.

Para o ponto de interesse, duas qualificações devem ser expressamente registradas. Heidegger afirma que o Dasein, existindo no modo de ser da impessoalidade, é um e não o ens realissimum. O uso do artigo indefinido denota que se trata de uma equiparação ao papel ontológico de tal conceito, e não que o Dasein seja pensável em termos teológicos. Por fim, mas de forma decisiva, a equiparação é qualificada por uma cláusula restritiva: ens realissimum, mas desde que "realidade" seja entendida em conformidade com a categoria ontológica da existência. Entes que são casos de Dasein não são adequadamente descritos como portadores de características de estado. O Dasein impessoal como ens realissimum não é, portanto, o conjunto da inteira realidade, e sua determinação, completa ou não, não é estabelecida em termos de conjunto de propriedades.

Como ens realissimum a impessoalidade é originária, no sentido de que é o modo no qual os existentes estão lançados em possibilidades na cotidianidade. Ele é o "sujeito mais real" da cotidianidade (SZ, s. 128). Consequentemente, todas as especificações possíveis da existência, na ruptura da cotidianidade, ou nas suas formas não medianas, têm como ponto de partida a impessoalidade. Assim, todas as modificações existenciais, autenticidade e inautenticidade, originam-se a partir do modo de ser impessoal. Isso significa que estes dois modos fundamentais de estar em possibilidades são definidos por relação ao modo impessoal de ser. Inautenticidade e autenticidade não podem ser vistos como distanciamentos de toda regra e normatização. Ao contrário, estas possibilidades de ordem superior delimitam maneiras especiais de instaurar desempenhos regrados, como formas peculiares de relacionamento com

Kant aparentemente subscreve o princípio de identidade dos indiscerníveis - mas pela impossibilidade de deteminarmos qualquer idéia da razão. Por uma sub-repção transcendental, a idéia do conjunto de toda a realidade é hipostasiada e realizada no conceito de ens realissimum, ao qual ainda vêm ligar-se predicados como originariedade, simplicidade e superioridade. Sobre o conceito de negação e afirmação transcendentais, bem como sobre o princípio da deteminação completa, ver Loparic (2000, pp. 122-28) . 
as regras dos papéis em que sempre se está (Mulhall, 1994, pp. 73-4). ${ }^{10}$

Como ens realissimum, o existente na impessoalidade é o fundamento a partir do qual especifica-se o princípio de individuação existencial. Ou seja, a facticidade do existente humano, as possibilidades lançadas em que se encontra, ainda não representa a sua inteira determinação como indivíduo singular. Esta somente pode ser concebida em termos existenciais como modificação das possibilidades, no sentido de uma modificação que toma como pressuposto a impessoalidade na definição das habilidades e dos papéis envolvidos. Em particular a modificação da impessoalidade para o modo autêntico pode ser visto como a formação de individualidade no interior de um domínio em que os particulares não são casos de gêneros (Macdounogh, 1998). Trata-se, portanto, de uma abordagem relacional da modificação de impessoalidade em autenticidade, que não são vistos como estados antagônicos, nem como condições temporalmente sucessivas.

Para coisas em geral, a individualidade é dada por relação ao ens realissimum, em termos de relações de participação e negação nas propriedades. No caso do existente humano, que é apenas modo e maneira de ser, trata-se de um tipo de modificação. Também aqui o impessoal não é visto como a totalidade das possibilidades existenciais, cujas restrições parciais seriam os indivíduos. Os modos inautêntico e autêntico de existir não são subconjuntos determinados a partir de um todo que seria o impessoal. Heidegger também ressalta, em consonância com a noção de ens realissimum, que o impessoal não é um gênero, um sujeito genérico do qual os indivíduos seriam casos. ${ }^{11}$ As negações como singularizações obedecem uma lógica de modos, cuja explicitação tem seu foco nas noções de possibilidade e modificação existenciais. Podemos agora iniciar a conclusão do presente trabalho, destacando expressamente o sentido da comparação entre a existência impessoal e a noção de ens realissimum.

\section{0 verdadeiro abismo para a razão}

A equiparação da impessoalidade com o ens realissimum atinge de modo central o conceito de fundamento. Como os $\operatorname{casos}^{12}$ de Dasein não possuem

10 Lemos em Ser e Tempo: "O ser si mesmo autêntico não repousa em um estado excepcional do sujeito, dissociado do impessoal, mas é uma modificação existenciária do impessoal enquanto um existencial essencial. (SZ, s. 130)"

11 Em 1927 Heidegger reconhecia que nem a Lógica tradicional, nem qualquer ampliação ou correção sua a partir das ciências do espírito poderiam conceitualizar adequadamente as relações formais que se abrem com a ontologia da existência.

12 Expressão de Haugeland (1982), tomada em sua acepção clínica, e não em sentido lógico, quando dizemos que um indivíduo é um caso que cai sob ou instância um conceito. 
propriedades, mas apenas maneiras de ser, não há um gênero ou essência determinada, com a qual deveriam buscar adequação ou realização. Também aqui "fundamento" não tem o sentido de justificação de alguma determinidade existencial (existenzial) ou existenciária (existenziell) específica. Trata-se da impessoalidade como fonte última da identificação e individuação ontológica, ou seja, a impessoalidade como limitação da projeção de ser, do sentido e da identidade ontológica em todas as direções da transcendência do $D a$ sein. ${ }^{13}$ Lembrando que ser Dasein significa desvelar ser, então a equiparação qualificada da impessoalidade com o ens realissimum significa que toda projeção e articulação de sentido obedece às determinantes formais de um normatização impessoal, interpessoal e social. Tanto compreensão quanto disposição de ânimo devem estar delimitados, em sua capacidade de abertura, pelo modo de ser impessoal (a Befindlichkeit também seria impessoalmente determinada). Qualquer modificação na articulação de sentido é sempre a partir da impessoalidade. A abertura de ser e o descobrimento de entes, portanto, têm como fundamento as definições formais da impessoalidade. As delimitações formais da impessoalidade são determinantes na projeção de sentido, logo, na estrutura do algo enquanto algo. Tamanho é o alcance da doutrina, que Heidegger pode concluir, ao responder a objeção de que a impessoalidade seria como um nada (pelo fato de não dispormos de categorias ontológicas para a sua conceitualização) que "devemos dirigir o próprio conceito de ser para este fenômeno irrecusável" (GA 20, s. 340). ${ }^{14}$ O próprio desvelamento de ser é demarcado pela impessoalidade, e toda modificação a toma como ponto de partida. E Heidegger afirma categoricamente:

"O próprio impessoal, em função do qual o Dasein é cotidianamente, articula a conexão de remissões da significatividade. O mundo do Dasein libera o ente que vem ao encontro a partir de uma totalidade de conformidade que é familiar ao impessoal, e nos limites que estão fixados com a medianidade do impessoal. "(SZ, s. 129)

Dado que a compreensão é elaborada em interpretação, sendo discursivamente articulada, a impessoalidade representaria a fonte primeira de toda inteligibilidade. Sentido e significatividade promovem igualmente a preservação da impessoalidade na própria discursividade e expressividade, isto é,

13 A este respeito, na literatura recente aconteceu um intenso debate acerca do significado ontológico fundamental da impessoalidade, sobre o qual não nos detemos agora. Não obstante, mesmo que exista um tensão nas formulações acerca da noção de impessoalidade (das Man), acreditamos que uma reconstrução ontológica e não normativa do conceito permite uma abordagem coerente com o inteiro projeto ontológico de Heidegger no períodb de Ser e Tempo. Ver: Olafson (1987, 1994, 1998), Dreyfus (1991, 1995), Carman (1994), e Boedeker (2001).

14 Em Ser e Tempo Heidegger utiliza uma formulação levemente modificada, empregando as expressões no plural (SZ, s. 128). 
na significação lingüística propriamente dita. Se é a partir da impessoalidade que toda projeção de ser ganha delimitação, e se é a partir da modificação da compreensão de ser cotidiana que surge a possibilidade de tematização, descrição, conhecimento e justificação, então a analogia entre a existência na impessoalidade e o ens realissimum está indicando precisamente o caráter de fundamento instituidor que a impessoalidade desempenha na abertura de ser e da inteligibilidade. ${ }^{15}$

Não obstante, mesmo sendo uma base primitiva irrecusável, a impessoalidade não é determinante da inteligibilidade em toda sua extensão. Ou seja, Heidegger admite que a impessoalidade ainda deve ser reduzida a um patamar diferenciado, no tocante ao seu papel de fundamento da compreensibilidade. A publicidade da impessoalidade obscurece tudo, diz Heidegger em Ser e Tempo (s. 127). O que está obscurecido não é um nível último de fundamentação, ao qual a impessoalidade deveria ser reconduzida e explicada funcionalmente. Precisamente o que é encoberto é a natureza existencial da própria impessoalidade, ou seja, que nela acaba a vigência do princípio de razão suficiente. ${ }^{16}$

Aqui é o ponto onde a reconstrução do modo de ser autêntico deveria ser introduzida, pois nela abre-se, não um fundamento para justificar as possibilidades normatizadas em que se está, mas precisamente a falta de tal fundamento, ou então, a instauração de novas possibilidades normatizadas. ${ }^{17}$ Queremos apenas registrar que a modificação para a autenticidade ainda é fundada na socialidade do Dasein, porque diz respeito a um mudança na relação com a impessoalidade. Não se trata de uma saída de toda norma e regra, mas uma modificação que pode ser conceitualizada em termos de explicitação e expressividade. ${ }^{18}$ Para esta reconstrução é preciso introduzir uma noção apresentada por Heidegger no final dos anos vinte, e que tem uma dupla relevância. De um lado, ela permite justificar documentalmente o uso das noções de regra e norma para a caracterização das possibilidades existenciais e da impessoalidade. De outro, ela limita o emprego destas noções, mostrando uma restrição no uso inqualificado do conceito de papel social, tomado como via explanatória da possibilidade existencial. Trata-se da noção de jogo (Spiel),

\footnotetext{
15 Guignon, 1983, e especialmente Dreyfus (1991, pp. 154-62) desenvolveram com destaque este ponto. 16 Ver Loparic, 1994 e Dreyfus, 1991, pp. 156-7.

17 Recentemente, Dreyfus (2000) transitou para esta posição, relativizando a força da afimação de que a impessoalidade seria a fonte de toda a significação e inteligibilidade.

18 o Dasein é um ente que tematiza, e nisso pode ser vista a sua historicidade própria, tomada em termos de explicitação da impessoalidade e formação de singularidade a partir dela (o que é base para a instauração de novas regularidades e possibilidades, exibindo claramente a dimensão relacional de autenticidade e inautenticidade).
} 
na apresentação ontológica feita na primeira Lição de Freiburg, no inverno de 1928-29. ${ }^{19}$

Introduzindo uma análise do termo "jogo", Heidegger pretende mostrar que a transcendência do Dasein possui a natureza do jogo. O sentido da expressão é muito delimitado, tanto para destacar a relação entre jogo, atividade e regra, quanto para enfatizar uma dimensão não evidente do conceito, e que seria a relevante para conceitualizar a transcendência. Partindo da expressão comum segundo a qual "há uma certa alegria (Freude) no jogar, Heidegger quer acentuar que o jogo é algo no qual nos encontramos, no qual estamos situados. Nós estamos em jogos, mas de um modo tal que sempre é possível a formação do jogo e da regra. Ou seja, Heidegger destaca o aspecto de formação (Bildung) vinculada da regra no próprio jogar. A transcendência é dada na projeção de ser pela compreensão de ser, pois o Dasein já está de posse da condições para descobrir entes. Se a transcendência é delimitada formalmente pela impessoalidade, então também esta obedece a determinação do jogo.

Examinando com mais cuidado, as habilidades nas quais o existente está lançado não podem ser vistas como formando papéis sociais. Ou melhor, o lançar-se nelas não é plenamente o desempenho de um papel, porque as possibilidades existenciais são essencialmente qualificadas como inalcançáveis (Blattner, 1999, pp. 81-8). É isso que fica revelado pelos fenômenos da consciência e do ser-para-a-morte. As possibilidades em que o existente está lançado podem deixar de importar, podem deixar de ser exercitadas. ${ }^{20}$ A possibilidade existencial somente é possibilidade enquanto o existente estiver projetando-se nela (SZ, s. 145). Circundadas pela possibilidade da impossibilidade, pela indisponibilidade última dos estados de ânimo, e pela irrecuperabilidade do ponto de partida da projeção existencial, as habilidades existenciais não são alcançáveis de modo definitivo. A modificação para a autenticidade é sempre uma possibilidade no horizonte, a partir da qual abre-se a perspectiva da decisão entre ser ou não ser propriamente o que já se é. Assim, também seria possível justificar uma interpretação funcional de tal modificação, num sentido teleológico. Ou seja, pela natureza mesma da transcendência impessoal, enquanto jogo que institui e desinstitui a significatividade, o modo de ser autêntico delineia-se como o telos permitido pela própria impessoalidade. $^{21}$

\footnotetext{
19 Não pretendemos aqui uma reconstrução suficiente da abordagem heideggeriana do conceito de jogo, mas apenas uma breve menção indicadora da continuidade do problema sob análise.

20 Aqui não está questão a decisão e a escolha de manter-se em possibilidades, mas sim que, por sua natureza existencial, elas dizem respeito a modalidades sem sustentação.

21 Com isso também ganharia consistência algumas das formulações de Heidegger, em particular a seguin-
} 
Porém, o exame desta questão excede os limites do presente trabalho. A título de conclusão, destacamos a direção de continuidade, retomando a comparação com a noção de ens realissimum. Mais uma vez, a comparação é em relação a Kant. Numa notável passagem da Crítica da Razão Pura, Kant escreve:

\begin{abstract}
"A necessidade incondicionada, que tão imprescindivelmente necessitamos como suporte último de todas as coisas, é o verdadeiro abismo para a razão humana. Mesmo a eternidade, por mais terrivelmente sublime que um Haller a descreva, nem de longe produz idêntica impressão de vertigem na mente, pois só mede a duração das coisas, mas não as porta. Não podemos nem evitar nem tampouco suportar o pensamento de que um ente, que nós representamos também como o supremo de todos os possíveis, por assim dizer, dissesse para si mesmo: eu sou de eternidade a eternidade, fora de mim não há nada senão aquilo que é algo apenas por minha vontade; mas de onde eu sou então? Aqui tudo se afunda sob os nossos pés, e tanto a máxima quanto a mínima perfeição pairam sem apoio simplesmente diante da razão especulativa, à qual não custa nada fazer desaparecer, sem o menor empecilho, tanto uma como a outra." (B 641)
\end{abstract}

Trazendo para a consideração a problemática de Ser e Tempo, em particular na afirmação de que o Dasein é um fundamento irredutível e nulificado, a impessoalidade pode ser vista como o ponto de chegada de toda pergunta pelo porquê. Sugerimos que, apesar de não ter um fundamento sobre o qual repousar a abertura de ser impessoalmente promovida pela existência, aqui não estamos diante do verdadeiro abismo, mas de um não fundamento ( $U n$ grund). ${ }^{22}$ A impessoalidade delimita a projeção de ser, e, mesmo em sua variação histórica, torna-se acessível algo como algo. Por mais vertiginoso que isso possa parecer, lançamos a hipótese de que, para o problema formulado por Heidegger, o abismo para a razão está em outro lugar, a saber, no acontecer ele mesmo da projeção de ser, que requer entes existentes para se instalar, mas ao mesmo tempo possui uma autonomia manifesta na própria independência histórica da impessoalidade. Mais propriamente, as condições que tornam possível qualquer relacionamento com objetos, social e impessoalmente determinadas de princípio, permitem que elas mesmas não sejam reconhecidas como tais. O abismo para a razão, para continuar na metáfora de Kant, estaria na própria historicidade do desvelamento e retraimento do ser.

te: "Autenticidade possível é fundamento de inautenticidade. inautenticidade designa um modo de ser no qual o Dasein pode se extraviar e, na maioria das vezes, sempre já se extraviou, sem que deva necessaria e constantemente se extraviar nele." (SZ, s. 159)

22 Não podemos analisar agora a distinção entre os significados dos termos Abgrund e Ungrund. Porém, mesmo que o Dasein impessoal não constitua os objetos como objetos, dele pode-se dizer que resulta uma instituição (Haugeland, 1982), que certamente não é neutra em termos de uma simples lista de categorias, mas cuja concretude pemite inclusive a manifestação das violências que próprio Dasein leva consigo (como muito enfaticamente apresenta Heidegger na referida Lição de 28/29, s. 326) . 


\section{Referências bibliográficas}

1. AMERIKS, K. The Critique of Metaphysics: Kant and traditional Ontology. In: GUYER. P. The Cambridge Companion to Kant. Cambridge: Cambridge University Press, 1992. pp. 249-279.

2. BLATTNER, W. Heidegger's temporal idealism. Cambridge: Cambridge University Press, 1999.

3. BOEDEKER, E. C. Individual and Community in Early Heidegger: Situating das Man, the Man-self, and Self-ownership in Dasein's Ontological Structure. Inquiry, 44, 63-100, 2001.

4. BRANDOM, R. Heideggers Categories in Being and Time. In: DREYFUS, H \& HALL, H. Heidegger: A Critical Reader. Oxford: Blackwell, 1992. pp. 45-64.

5. CARMAN, T. On Being Social:A Reply to Olavson. Inquiry, 37, 202-23, 1994.

6. CHRISTENSEN, C. Heidegger's Representationalism. The Rewiew of Metaphysics: 51, 77-103, 1997.

7. DELL'ORO, R. O. M. From Existence to Ideal. Continuity and Development in Kant's Theology. New York: Peter Lang, 1994.

8. DREYFUS, H. A Commentary on Heidegger's Being and Time, Division I. Cambridge Massachusetts: The MIT Press, 1991.

9. Interpreting Heidegger on das Man. Inquiry, 38, 423-30, 1995.

10._Could anything be more intelligible than everyday intelligibility? Reinterpreting division I of Being and Time in the light of division II. In FAULCONER, J. \& WRATHALL, M. Appropriating Heidegger. Cambridge: Cambridge University Press, 2000. pp. 155-174.

11. GUIGNON, C. Heidegger and the Problem of Knowledge. Indianapolis: Hackett Publishing Company, 1983.

12. HAN, B-C. Martin Heidegger: eine Einführung. München: Wilhelm Fink Verlag, 1999.

13. HAUGELAND, J. Heidegger on Being a Person. Noûs, 15-26, 1982.

14. HEIDEGGER, M. Sein und Zeit. 17. ed. Tübingen: Max Niemeyer Verlag, 1986.

15. Die Grundprobleme der Phänomenologie. 2. ed. In: Gesamtausgabe 24 (Sommersemester 1927). Frankfurt am Main, Vittorio Klostermann, 1989.

16. Einleitung in die Philosophie. In: Gesamtausgabe 27 (Wintersemester 1928/29). Frankfurt am Main, Vittorio Klostermann,1996

17. Phänomenologie und Theologie. In: Gesamtausgabe 9. Frankfurt am Main, Vittorio Klostermann,1996.

18. HENDRICH, D. Der ontologische Gottesbeweis. Tübingen: J. C. B. Mohr, 1967. 19. KANT. I. Kritik der reinen Vernunft. Hamburg: Felix Meiner, 1956.

20. LOPARIC, Z. Ética e Finitude. In: NUNES, B. A Crise do Pensamento. BelémPará, Editora Universitária, 1994.

21. __ O princípio da bivalência e do terceiro excluído em Kant. Studia Kantiana, (2) 1, 105-137, 2000. 
22. LUCKNER, A. Martin Heidegger: "Sein und Zeit": ein einführender Kommentar. Paderborn: Verlag Ferdinand Schöningh, 1997.

23. MCDOONOUGH, R. Heidegger on Authenticity, Freedom, and Individual Agency: na Aristotelian Model. International Studies in Philosophy, (30) 2, 69-91, 1998.

24. MULHALL, S. Heidegger and 'Being and Time'. London: Routledge, 1996.

25. OKRENT, M. Heidegger's Pragmatism. Understanding, Being, and the Critique of Metaphysics. Ithaca: Cornell University Press, 1988.

26. OLAVSON, F. A. Heidegger and the Philosophy of Mind. New Haven: Yale University Press, 1987

27. Heidegger à la Wittgenstein or 'Coping' with Professor Dreyfus. Inquiry: 37, 45-64, 1994.

28. Heidegger and the Ground of Ethics. A Study of 'Mitsein'. Cambridge: Cambridge University Press, 1998.

29. SALA, G. B. Kant und die Frage nach Gott. Berlin: Walter de Gruyter, 1990.

30. SMITH, N. K. A Commentary to Kant's 'Critique of Pure Reason'. New York: Humanities Press, 1962.

31. WOOD, A. Rational Theology, moral Faith, and Religion. In: GUYER. P. The Cambridge Companion to Kant. Cambridge: Cambridge University Press, 1992. pp. 394-416. 